\title{
MOCIDADE MORTA: A VIDA NA ARTE DO SÉCULO XIX
}

\section{Alexandra Filomena Espindola*}

\begin{abstract}
Resumo: Este ensaio pretende ler o romance Mocidade Morta, de Gonzaga Duque, e fazer algumas comparações entre a vida e a arte do século XIX. Gonzaga Duque utiliza alguns acontecimentos e personagens de sua época em seu livro, o que confere ao romance um caráter realista na arte. Ao longo dos capítulos, a arte vai se apropriando do "real"; se, como afirma Rancière, o real precisa ser ficcionado para ser pensado, a arte é, por excelência, lugar privilegiado para pensarmos a vida.
\end{abstract}

Palavras-chave: Mocidade Morta. Arte. Vida.

O romance de Gonzaga Duque, Mocidade Morta foi publicado em 1899, depois de muitos problemas com a edição, que saiu com vários erros gramaticais, os quais valeram algumas páginas no diário de Gonzaga Duque, publicado por Vera Lins (1991). Também alguns críticos receberam muito mal esse romance, fazendo com que o autor perdesse algumas noites de sono. Esta ilustração abaixo (Figura 1) é de Calixto Cordeiro, caricaturista carioca que também ilustrou o conto "Morte do Palhaço", de Gonzaga Duque. Calixto sabe da história do autor e do romance e desenha (acima de um "poeminha") uma situação de salvação, pois, depois de tantos sacrifícios, Gonzaga Duque com o chapéu na mão e seu romance na mala merece o céu. No "poeminha":

\footnotetext{
Subiu, coitado, sozinho

Muito triste e surumbatico

Bateu no Céo de mansinho

- Todos no Céo acordaram -

E onze mil virgens gritaram;

"Entra, sympathico"
}

Mocidade Morta é considerado o primeiro romance simbolista brasileiro. Além do caráter simbolista, esse romance carrega muitos traços da literatura realista/naturalista, com toda uma crítica social direta, um descontentamento com a Academia de Artes, um retrato do final do século XIX. Simbolista ou não, o que já de início nos chama a atenção é a epígrafe que abre o livro:

\footnotetext{
deixa, um instante, o cuidado quotidiano que te cansa, deixa mesmo as estéticas que louvaram um após o outro realismo e idealismo; acredita que nunca houve antagonismo entre Real e o Ideal, mas que é da sua fusão que é feita a Vida... e toma, simplesmente, como eu te dou, este pouco de mim (VIELÉ-GRIFFIN apud DUQUE, 1995) ${ }^{1}$.
}

\footnotetext{
* Doutora em Ciências da Linguagem pela Universidade do Sul de Santa Catarina (UNISUL).

${ }^{1}$ François Vielé-Griffin (1864-1937), poeta simbolista.
} 
Figura 1 - Ilustração de Calixto Cordeiro

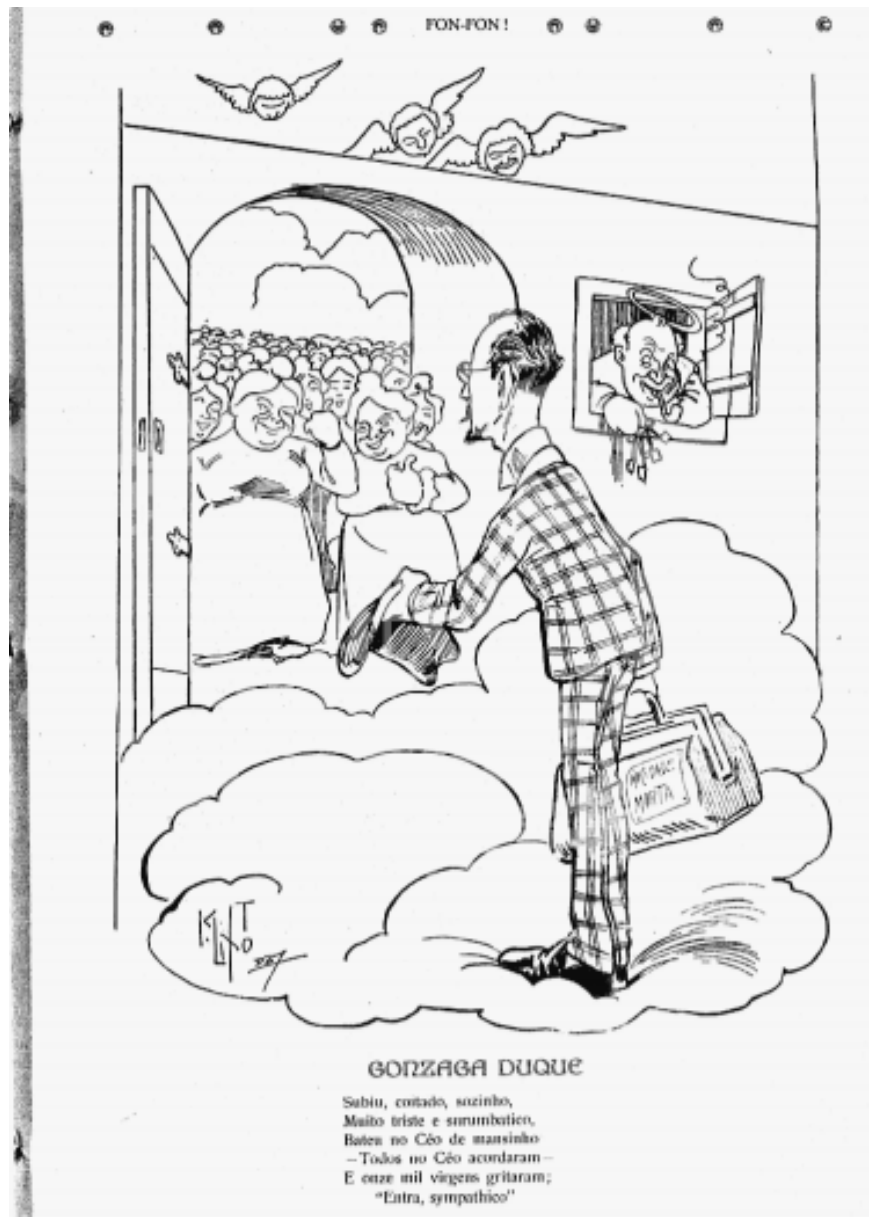

Fonte: Revista Fon Fon, n $^{\circ}$, abril de $1907^{2}$.

Por hora, deixemos essas palavras de Vielé-Griffin para que possamos retomá-las depois. Alexandre Eulálio, em "Estrutura narrativa de Mocidade Morta" (EULÁLIO, 1995, p. 278), observa que o romance de Gonzaga Duque "se apóia nas coordenadas estéticas do Impressionismo naturalista [...]; o ficcionista procura superar a pulverização narrativa, inseparável da estenografia impressionista, conciliando-a com os procedimentos tradicionais do Realismo verista". Eulálio vê os capítulos XIV e XVII como passagens pouco resolvidas, fastidiosas e de rasa literalidade, pois se apresentam com estrita obediência naturalista. Para ele, Gonzaga Duque contempla imperativos do determinismo biológico, aparecendo na infraestrutura determinista "que enforma a visão de mundo de Gonzaga Duque [...]. A epígrafe de Vielé-Griffin que ele escolheu para abrir o romance é bem clara a esse respeito" (EULÁLIO, 1995, p. 283).

\footnotetext{
${ }^{2}$ Revista Fon Fon, no 1, abril de 1907. Disponível em: <http://objdigital.bn.br/acervo_digital/ div_periodicos/fonfon/fonfon_1907/fonfon_1907_001.pdf>. Acesso em 19 de outubro de 2013.
} 
Em Gonzaga Duque, a estratégia do franco atirador, Vera Lins publica o diário de Gonzaga Duque, em que se encontra uma carta que ele recebe em janeiro de 1900 de seu amigo Nestor Victor. Este crítico reserva as seguintes palavras sobre o romance:

\begin{abstract}
já li tua Mocidade Morta. É uma Obra, o teu livro: curiosíssimo, pessoalíssimo representando toda uma honesta vida de emoções, de lavor, e de estudo. É um livro-estuário, que neste ponto não tem seu igual em nenhum outro de prosador brasileiro que eu conheça, até hoje. Fazes lembrar o lento, incontestável e nobre Flaubert (VICTOR apud LINS, 1991, p. 142).
\end{abstract}

Essa analogia já nos leva a ler com os olhos atentos na procura por uma dose de realismo/naturalismo neste livro. O romance abre com a exposição de um quadro imenso, de 14 x 12 metros, pintado por Telésforo de Andrade. A descrição do quadro nos faz vêlo com nitidez, tamanha a preocupação com os detalhes que a compõe, uma descrição de cunho realista/naturalista:

\begin{abstract}
vasto painel na sua grandeza de catorze metros, enchendo o alto fundo do panteão, de relance - o peso safiroso da abóbada caindo numa gradação lenta para o cinábrio vago das auroras crescentes, e ao demorar da vista - nuanças esbatimentos vaporosos, um calor aéreo de amarelos, panos de muros, numa torre alvejando lá embaixo, violáceas sinuosidades de coxilhas... E para o meio da tela, em disposições intermediárias, na tenuidade de uma fumaraça branca, apareciam listas de lâminas, bonés de soldadesca em pelotões consecutivos, distendendo-se, coleando pelo declive do terreno remoto, diminuindo, confundindo-se, a distância, num tom impreciso de debuxos e esmaecimentos de cor. Agora, nos planos próximos, os relevos se acusavam, brilhavam as tintas: feições pasmadas de infantes a meio corpo, armas esguias de bandeirolas frementes de um esquadrão de lanceiros, duas manchas auriverdes de estandartes desfraldados, uma, vaga, atormentada na eterização branda da longitude; outra, perto, mais larga, mais colorida, batendo ao vento sobre a floresta de aço dos batalhões... Dominando a ampla planimetria do fundo erguia-se o grupo principal, sobre um barranco que formava o primeiro plano e esboroava-se num declive brusco, tortuoso e extenso; na curva desse caminho surgia, numa cavalgata de generais, o uniforme vermelho de um chefe inimigo. À frente do grupo dominante, o imperador estacara o seu hidrópico e grande cavalo branco. $\mathrm{O}$ sr. d. Pedro, mão à rédea, o braço de espada apoiado pelo pulso do cinturão lavrado, fitava com altivez o prisioneiro de guerra, que se aproximava; o seu corpanzil esganchado na cavalgadura, tinha a eretibilidade dos invencíveis, a que um poncho de gaúcho, atirado pelos ombros, aumentava de arrogância. Guardava-o um simétrico estadomaior, elevadas patentes do exército, nobres nos seus fardões de gala, com a fulguração marchetada de medalhas e insígnias... (DUQUE, 1995, p. 21-22).
\end{abstract}

Tamara Quírino, no ensaio "Comentários e críticas de Gonzaga Duque a Pedro Américo" (2006), publicado na revista 19\&20, supõe que Gonzaga Duque tenha se inspirado em Pedro Américo para criar o personagem Telésforo, pois há alusões à pessoa do pintor da Academia, como: educado na Europa, possui favores do imperador e fez telas com temas bélicos de 1865 a 1870. Eulálio (1995) também reconhece Pedro Américo em Telésforo, mas também Victor Meirelles e outros, como se Telésforo fosse uma espécie de personagem-síntese, em cujos elementos estão fundidos diversos artistas. A literatura e a história se envolvem, se referem, vida e arte, ficção e "realidade". Nessa relação ou imbricação, caberia uma daquelas acusações simplistas da crítica: o realismo/naturalismo não cria, relata, ou seja, descreve o que estuda, o que observa, não como um trabalho de artista, mas de cientista. 
A descrição do quadro e do evento serve de mote para a apresentação de "um pequeno grupo de rapazes. Eram quatro Insubmissos de vestes coçadas e jovialidade boêmia": Camilo Prado, Franklin, Artur de Almeida e Sabino. O primeiro é tido como alter-ego de Gonzaga Duque, o que faz com que arte e vida se invadam, se misturem novamente. Por mais que literatura não seja documento, a imbricação de arte e vida nos traz incertezas juntamente com a possibilidade de criar "realidades".

Em Mocidade Morta, Gonzaga Duque se descreve tanto fisicamente quanto intelectualmente na figura de Camilo Prado: "era um anêmico escanifrado com ares de fidalguia abastarda, vago olhar cinzento, umedecido pelas dolências das tuberculoses incipientes e pequeno bigode de fios liso, à chim" (DUQUE, 1995, p. 17). Já de antemão, podemos dizer que os personagens de Mocidade Morta não são tipos ideais, mas criaturas que vivem e circulam no mundo da arte de maneira muito semelhante ao "mundo-láfora". George Didi-Huberman, em "La imagen-matriz: historia del arte y genealogia de la semejanza", do livro Ante el tiempo: Historia del arte y anacronismo de las imágenes (2006, p. 101), arrisca dizer que as relações dão vida e significado aos objetos, mais especificamente, as relações de semelhança. Essas relações são tanto eleições teóricas quanto "filosofia espontânea". Já Ernest Fischer, em $A$ necessidade da arte, após descrever brevemente como a semelhança começa a ter papel funcional na vida do homem primitivo (fabricar um instrumento semelhante a outro também útil), passa a dissertar sobre a semelhança no nível da abstração, das complexidades. Ainda de acordo com Fischer, "a realidade nunca é um acúmulo de unidades separadas, existentes umas ao lado das outras, sem conexão entre elas. Todo 'algo material' é conexo a outros 'algos materiais'; entre os objetos há uma vasta variedade de relações". A semelhança é uma arma, uma força mágica, que faz com que as relações criem "realidades" (FISCHER, 2002, p. 41). Assim se desenvolve Mocidade Morta.

O grupo de Insubmissos organiza-se numa pretensão avant garde para criar uma "arte nova", contra as botas acadêmicas ${ }^{3}$. Esse grupo e suas ideias têm uma relação muito forte com os "artistas revolucionários" do final do século, semelhante ao que viveu Gonzaga Duque, que participou ativamente do projeto realista/naturalista e da roda simbolista, juntamente com Raul Pederneiras, Cruz e Sousa entre outros. Ao grupo agrega-se Agrário de Miranda, figura que traz consigo uma crítica aos concursos de viagem e ao sistema de apadrinhamento da Academia. Gonzaga Duque acompanha a constituição tímida do campo da arte no Brasil e está presente no debate sobre o desenvolvimento e os procedimentos das academias. Aqui a literatura rouba a história "real" da vida dos artistas brasileiros e a aproveita para discutir as questões da arte. Clementino Viotti assemelha-se com Cruz e Sousa. No romance, o narrador descreve-o como "arquiteto sem viagem"; na "vida real", o poeta é um arquiteto das palavras, sem viagem, sem fortuna, sem sorte, também abandonado pela Academia. Clementino Viotti é descrito em meio ao grupo desta maneira:

n'ardência de sua imaginativa de mestiço, combinação de violências coloridas de um italiano de Nápoles com o lirismo contemplativo de uma mulata patrícia, se não se arrancava fulo, convulsivo, tremendo, em objurgatórias contra a "pobre Academia e a infame Sociedade", bramava como um João Batista precursor, apostrofando o antiesteticismo arquitetural da metrópole, por ele sonhada em maravilhoso conjunto de soberana graça e gloriosa força -

${ }^{3}$ Bota é o nome dado à tela mal feita, sem valor. 
serenidades atenienses e grandezas d'Oriente - a deslumbrar Civilizações na Ribamar da Guanabara encantadora, espumejante d'efervescências cérulas ${ }^{4}$ sobre o alabastro de escadarias monumentais (DUQUE, 1995, p. 31).

Em Impressões de um amador, Gonzaga Duque afirma que Cruz e Sousa sofria de "mal de São Vito" (santo católico que morreu após ser perseguido por imperadores romanos em 303 d.C.), pois o poeta se sentia oprimido por sua condição de negro e "de quando em quando, ele me aparecia nervoso [...] a queixar-se que fugira da Repartição porque o chefe, que era mulato, o perseguia e hostilizava" (DUQUE, 2001, p. 333).

Conhecendo a crítica de Cruz e Sousa à sociedade preconceituosa e beata, já o reconhecemos, então, nestas palavras de Viotti, que pouco aparecem na narrativa: "nesta terra tudo está torto, desde a consciência dos homens até a calçada das ruas" (DUQUE, 2001, p. 32). Gonzaga Duque, participante e defensor do poeta simbolista, utiliza uma linguagem típica dos simbolistas nessa passagem, numa dobra da arte na arte: é a crítica de arte simbolista falando da arte simbolista com a linguagem simbolista. A escrita de Gonzaga Duque, segundo Vera Lins (2009, p. 77), "é uma constate ultrapassagem dos limites dos gêneros", uma vez que seu romance traz um tom ensaístico e seus ensaios têm um caráter literário. Além disso, Gonzaga Duque "parece querer realizar com seu romance todas as inovações do final do século, que diz desconhecidas pelo grupo dos Insubmissos, alternando passagens naturalistas, impressionistas e simbolistas" (LINS, 2009, p. 188).

O grito dos Insubmissos é contra a Academia Imperial ${ }^{5}$, pois a narrativa se passa na época do Império, visto que a princesa Isabel compareceu à inauguração da tela de Telésforo, pois estava exercendo, naquele momento, a Regência do Império na ausência de seu pai, que se encontrava na Europa em tratamento de saúde.

É importante observamos que, na roda dos insubmissos, não encontramos referências aos simbolistas, somente a voz do narrador ao fazer descrição de Viotti transcrita acima. Os Insubmissos se parecem mais com um grupo de artistas do final do século - um grupo híbrido, em que se deixa ver impressionistas, realistas/naturalistas, simbolistas e parnasianistas. O personagem Pereira Lemos é assim caracterizado pelo narrador: "autor de caprichosos sonetos parnasianos, dum fino relevo de cinzel helênico, que imprimia aos preferidos assuntos mitológicos a correção dos perfís clássicos" (DUQUE, 1995, p. 29).

Com o orgulho ferido por não ter conseguido um Prêmio de Viagem e também por não fazer parte da Academia, Agrário faz injúrias contra a Instituição. Já Camilo vê as deficiências do ensino acadêmico e deseja fazer um movimento contra a tradição, sem protestos e sem barulho. Ele então propõe para Agrário iniciar uma "nova arte", mais especificamente, uma arte impressionista, como na Europa. Para Camilo, os artistas brasileiros não são criadores, mas continuadores da preceptora espiritual - a Europa. Como estava lendo sobre o auge do impressionismo, falava muito "de seus processos, dos seus exageros, das suas vantagens pinturescas (...). Camilo discorria sobre as telas impernitentes de Édouard Manet, sobre as paisagens vernais de Pissarro e os motivos escandalizantes de Caillebotte" (DUQUE, 1995, p. 33).

${ }^{4}$ A partir de cerúleo, que significa azul-celeste, verde-mar.

${ }^{5}$ No Império, Academia Imperial de Belas-Artes (AIBA), depois, na República, Escola Nacional de BelasArtes (ENBA). 
Ao mesmo tempo em que palestrava sobre os impressionistas, falava do reformador Zola, defensor da "escola de Manet", como se lê em A batalha do impressionismo. Além de citá-lo, Gonzaga Duque, muitas vezes, segue o modelo de Zola, principalmente quando fala sobre a ligação entre o temperamento do artista e a produção deste, uma vez que, no objeto de arte, está a individualidade do artista. Em conversa com Agrário, Camilo aconselha o colega:

\begin{abstract}
- Oh! senhor... Nada mais simples: aproveita o teu talento, entrega-te à tua própria idiossincrasia. Toma a tua palheta, vai para a natureza, estuda-a, observa, revolve, esmiúça, procura nela o que ela há de ter unicamente para a tua visualidade, fixa essa nota, desenvolvea, vive para ela, dá-lhe a tua alma...

- E depois? [questiona Agrário]

- Depois, terás conseguido a tua arte, nota bem - a tua arte - e outros virão fazer com a mesma independência, animados pelo exemplo triunfante do teu lutar. Depois cairão os estafados preceitos do academicismo, o sistema-métrico das concepções guiadas, os dogmas estéticos do ensino oficial. Aí tens tu, é o início da revolução com que sonho (DUQUE, 1995, p. 40).
\end{abstract}

Essa revolução almejada vai culminar no modernismo paulista, na nossa leitura, uma vez que os processos artísticos do século XIX deram condições para que o XX transformasse a arte a ponto de outras concepções e modos de fazer pudessem surgir. Camilo propõe tudo isso a Agrário porque o considera um Manet brasileiro, assim como Gonzaga Duque se refere a Roberto Mendes, a quem dedica páginas de artigos para periódicos a elogiar esse pintor. No ensaio "Paizagens: Roberto Mendes", do livro Contemporâneos: pintores e escultores (1929), compilação de textos publicados em periódicos, Gonzaga Duque caracteriza Roberto Mendes como um reformador e traz uma frase de Vitruvio Polio: "não se deve estimar a pintura que não se pareça com o real"6 (POLIO apud DUQUE, 1929, p. 35). Essa habilidade, segundo Gonzaga Duque, Roberto Mendes tem, pois o crítico sente as ervas molhadas na paisagem do pintor.

Logo os Insubmissos enfraquecem. O mais motivado contra a Academia é Agrário, mas começa a se ocupar com a francesa Henriette. Ela é uma moça comum, mulher de um cambista. Rancière afirma que o século XIX é a época da prosa, uma arte que não somente fez uma revolução estética, mas uma mais perturbadora ainda, "as hierarquias tradicionais da ação que haviam dado suas leis e hierarquias às belas letras e às belas artes foram abolidas em benefício da igualdade da vida"7 (RANCIÈRE, 2013, p. 193). Essa paixão (sentimento comum a qualquer um) faz com que Agrário abandone os assuntos de arte e se deixe levar por essa relação a ponto de fugir com a moça.

Camilo confiava que o único capaz de começar uma revolução na arte de pintar seria Agrário, mas logo percebeu que este tinha apenas interesses particulares, tanto que, após perder o padrinho que o colocaria no concurso de viagem, uniu-se aos Insubmissos. Quando, mais tarde, conseguiu uma oportunidade de estudar em Paris, deixou o grupo, deixou Henriette desamparada e partiu. Dela foi que veio o jargão do grupo: Zut (interjeição francesa), que, segundo Camilo, "nada significava - isto é o que serve"

\footnotetext{
${ }^{6}$ Tradução nossa. Na transcrição de Gonzaga Duque: "mai non si debbomo stimari pitture quelle che non sono simili al vero".

${ }^{7}$ Tradução nossa. Em castelhano: "las jerarquías tradicionales de la acción que habían dado sus leyes a las jerarquías de las bellas letras y las bellas artes quedaban abolidas en beneficio de la igualdad de la vida".
} 
(DUQUE, 1995, p. 79). Já de acordo com Vera Lins (2009, p. 175), zut é “uma interjeição simbolista que significa 'basta'". Mesmo com um certo reconhecimento, o Zut, logo que nasce, começa a se desfazer. Telésforo, por exemplo, teme as vozes do grupo. Mas o Zut só trouxe desgraça aos jovens revolucionários. Camilo perde seu emprego no periódico A Folha, outros não são aceitos na Academia, e a arte "nova" não floresce.

Camilo, assim como Gonzaga Duque, é um estudioso: lê livros sobre história da $\operatorname{arte}^{8}$, escreve passagens sobre cortesãs antigas, "reconstruções de idades remotas, a vida íntima da civilização primitiva do Ocidente" (DUQUE, 1995, p. 64). Em conversa com Agrário, Camilo confessa que partiu da mitologia para o idealismo cristão, argumentando que interpretar a religião cristã, Os Símbolos na Arte, título de seu livro, é "penetrar em um novo mundo para a arte futura" (DUQUE, 1995, p. 161).

Para Camilo, a arte "nova" deveria mostrar a alma brasileira e, acima de tudo, ser uma arte idiossincrática e bem estudada no "natural”. Essa arte não era a das Academias, pelo contrário. Contra a Academia, Camilo escreve um artigo destinado ao periódico $A$ Folha, o que lhe rendeu a demissão. Essa arte antiacadêmica é denominada pelo narrador de "realidade pura, a eterna Verdade!". A crítica, porém, não se dá apenas à arte acadêmica, mas à sociedade daquela época, aos próprios brasileiros:

\begin{abstract}
- Somos assim, meu caro senhor Agrário, somos assim. Não temos perseverança nem idéias; quando muito pedimos emprestado à França, a Portugal mesmo, duas idéias que não compreendemos mas que nos trazem o deslumbramento da novidade, e começamos a dançar em derredor dela, como selvagens, em torno de um manipanso ${ }^{9}$. Somos assim, meu amigo, e por isso seremos, eternamente, uns imitadores, minados pela ociosidade, aterrorizados pela obstinação das criações, preteridos pela imbecilidade ovante... (DUQUE, 1995, p. 78).
\end{abstract}

Lembremos que o realismo/naturalismo já foi tido como um estudo especulativo do social, assim, o local de trabalho do artista deixa de ser o atelier e passa a ser o laboratório. Muitas vezes, Gonzaga Duque vê artistas com muita técnica e pouca sensibilidade, o que os torna imitadores. Como já vimos na epígrafe, Gonzaga Duque acredita que a arte é produto de observação com a idiossincrasia do artista (além de estudo), ou seja, mesmo na arte realista/naturalista, o "real" e o "ideal" estão imbricados. Todas essas referências à "realidade", como a política da Academia Imperial de Belas-Artes (AIBA), os pintores dessa instituição, a paisagem carioca e até mesmo as descrições de Camilo que correspondem a Gonzaga Duque dão a essa narrativa o estatuto de semelhança, pois a trama mostra, além de situações possíveis na vida nos últimos anos do Império, semelhanças nítidas com o que aqui se passava no final do século ou, pelo menos, uma versão próxima do que se passou. Temos a impressão de que o realismo/naturalismo pretendeu fazer da história matéria da arte de maneira que o testemunho tivesse lugar privilegiado, e a arte um artifício, em segundo plano, para fazer ver o social e o individual daquele tempo e espaço específicos. Nesse sentido, vale notar que vemos um mise-enabyme no início da narrativa quando, logo após a descrição da tela de Telésforo, aparece o título de uma tela de Pedro Américo - "Rendição de Uruguaiana - 28 de setembro de $1865 "$ - e os espectadores do quadro apontavam para os personagens, reconhecendo-os

\footnotetext{
${ }^{8}$ É importante lembrar que Gonzaga Duque escreve dois livros de história: A arte brasileira, em que fala das primeiras manifestações artísticas no Brasil até o final do século XIX. O outro livro é Revoluções Brasileiras: resumos históricos, que disserta sobre as principais, segundo ele, revoluções no Brasil.

${ }^{9}$ Manipanso: feitiço ou ídolo africano.
} 
como pessoas "reais". Essa identificação com pessoas "reais", essa semelhança faz com que a vida e a ficção se confundam, deixando ver mais "realidade" do que "ficção", mais vida do que arte.

Em Políticas da escrita, Rancière (1995, p. 7) vê o escritor em seu papel político ao afirmar que "escrever é uma maneira de ocupar o sensível e de dar sentido a essa ocupação". No intento de ocupar seu lugar no campo das artes, como um primeiro passo, os Insubmissos planejavam fazer uma exposição de seus trabalhos. Primeiro, foi adiada por falta de local apropriado; depois, pela falta de trabalhos. Podemos fazer uma comparação com a primeira fase do modernismo brasileiro, pois Mário de Andrade diz que, no primeiro momento modernista, houve uma preocupação tão grande com a invenção de uma "arte nova" que a criatividade ficou esquecida. Os Insubmissos até tentaram fazer um abaixo-assinado pedindo um ensino livre de instituições, mas também não deu em nada. Mais tarde, definiram o Zut como um acontecimento, mas que não acontece, pois a própria imprensa barrou. Na voz do personagem Lourival:

\begin{abstract}
- a imprensa! A imprensa entende tudo de arte como eu de sânscrito. Não há muitos dias, encontrei o Conselheiro Costa Vargas extasiado de admiração diante de uns quadrinhos de mais reles, da mais infame carregação de bazar, e o chefe deste nosso Camilo, que publicou dous artigos sobre as decorações da Capela Sistina, perguntava-me, uma ocasião, o que vinha a ser pintura a fresco! Aí está o que vale essa cousa informe, pegajosa e incolor que se chama crítica de belas-artes no jornalismo indígena. Aqui tem o nosso amigo, diante de seus olhos, um exemplo das habilitações dessa crítica: aqui me tem, a mim, Lourival d'Abreu, que apanhou nos livros umas tintas de arte e prepara neurastenias com o esforço de receptividade das suas células emocionais (DUQUE, 1995, p. 108).
\end{abstract}

Afinal, como falou Franklin: "que fazer?... Tudo perdido. A Academia estava com a força, tinha a imprensa, tinha a sociedade, tinha o governo" (DUQUE, 1995, p. 118), e os Insubmissos tinham o desalento, o desamparo, não tinham nem mesmo uma proposta de revolução.

Depois que Agrário foi estudar em Paris, Camilo ficou cuidando de Henriette, que adoecera. Ele, já apaixonado, dedica-se integralmente a ela, mas, sem coragem de se declarar, acaba perdendo-a para um político, que a leva para Pernambuco. Camilo cai numa profunda desolação e chega até mesmo a pensar em suicídio. Vera Lins, em "Zola e Gonzaga Duque: o artista e a cidade na virada do século", entende que é aí que "Gonzaga Duque parece partilhar com Zola o determinismo. Camilo, o personagem principal tem uma história familiar complicada com pai que se suicidou e fica claro que não vai se desvencilhar da situação" (LINS, 2011, p. 17).

Temos a impressão de que Gonzaga Duque, além de querer "registrar" a história da arte de seu século, intenta também "mostrar" a condição pessoal dos artistas, que, em geral, têm dificuldades de se estabelecer naquele campo tão restrito da arte no Brasil, que se restringia à Academia, ou seja: ou se era acadêmico ou não se era artista de importância. Rancière observa que o escritor é

\footnotetext{
o geólogo ou o arqueólogo que viaja pelos labirintos do mundo social e, mais tarde, pelos labirintos do eu. Ele recolhe os vestígios, exuma os fósseis, transcreve os signos que dão testemunho de um mundo e escrevem a história. A escrita muda das coisas revela, na sua prosa, a verdade de uma civilização ou de um tempo, verdade que recobre a cena outrora gloriosa da "palavra viva" (RANCIÈRE, 2009, p. 38).
} 
Rancière diz ainda que a história da literatura no século XIX é o discurso da agitação e da superfície, pois,

\begin{abstract}
no período naturalista e simbolista, ela [a palavra] se tornará destino impessoal, hereditariedade, cumprimento de um querer-viver destituído de razão, ataque às ilusões da consciência pelo mundo das forças obscuras. A sintomatologia literária mudará então de estatuto nessa literatura das patologias do pensamento, centrada na histeria, no "nervosismo" ou no peso do passado, nessas novas dramaturgias do segredo velado, em que se revela, através de histórias individuais, o segredo mais profundo da hereditariedade e da raça e, em última instância, do fato bruto e insensato da vida (RANCIÈRE, 2009, p. 38-39).
\end{abstract}

Essa literatura, ainda de acordo com Rancière, reproduz o sem-sentido da vida, em que se encontra a desordem das relações entre o visível e o dizível, entre o saber e a ação, entre a atividade e a passividade, características da revolução estética operada no realismo romanesco, ou seja, a identidade dos contrários, como vemos em Mocidade Morta. Voltando ao final da narrativa, após dois anos daquela exposição de Telésforo (agora diretor da AIBA, assim como foi Pedro Américo), os jovens artistas do Zut caem em desgraça, com exceção de Agrário. Um morre, outro enlouquece, outro se subordina a qualquer trabalho e Camilo, desempregado, longe de sua amada, sai pela cidade, questionando a vida, agora assombrada pela tuberculose: "por que lembrar a morte quando se tem mocidade?” (DUQUE, 1995, p. 233). Após muito caminhar, começa a tossir e pigarrear sangue, quando

\begin{abstract}
rápido, o rosto cavou-se-lhe de terror, e arquejou, de olhar doudo, assombrado com a mancha rubra, que estalara nas pedras, todo ele abalado, revolvido numa alucinação que se cingia às contorções agonizantes de duas exaustas forças opostas, a procurarem se desligar e a se estreitarem dolorosamente. Uma, tendendo a abater-se, cansada, desanimada, inerme; outra, impelida para o espaço, resistindo impotente, arfando por se desprender do peso que a levava para uma queda sem termo... E nesse uivante redemoinho glácido, o sopro morno de um derradeiro alento trazia-lhe à confusão do cérebro: notas de uma surdina de harpa que se exala, relâmpagos de pensamentos em que se debuxam cenários de fantascópios, frases entrecortadas, envolvidas na inefável tristeza dos murmúrios extremos, nas reticências dos soluços: “... a gente parte, a sorrir e confiada... para o horizonte... sob o claro tempo das boas promessas... E nunca mais volta!.. . e nunca mais volta !...” (DUQUE, 1995, p. 236-237).
\end{abstract}

Mocidade Morta termina com uma das mais antigas preocupações humanas, como nos diz a filosofia - o fim.

\title{
REFERÊNCIAS
}

DIDI-HUBERMAN, Georges. Ante el tiempo: Historia del arte y anacronismo de las imágenes. Buenos Aires: Adriana Fidalgo editora, 2006.

DUQUE, Gonzaga. Mocidade morta. Apuração do texto (segundo a edição de 1899), notas e o estudo "Linguagem e estilo de Mocidade morta" por Adriano da Gama Kury; notas e o estudo "Estrutura narrativa de Mocidade morta" por Alexandre Eulálio. Rio de Janeiro: Fundação Casa de Rui Barbosa, 1995.

Contemporâneos. Rio de Janeiro: Fabricante Typ. Benedicto de Sousa, 1929.

Impressões de um amador. Belo Horizonte: UFMG, 2001.

EULÁLIO, Alexandre. "Estrutura narrativa de Mocidade Morta". In: DUQUE, Gonzaga. Mocidade morta. Rio de Janeiro: Fundação Casa de Rui Barbosa, 1995. 
FISCHER, Ernest. A necessidade da arte. $9^{a}$ ed. Tradução de Leandro Konder. Rio de Janeiro: Guanabara Koogan, 2002.

LINS, Vera. Gonzaga Duque: a estratégia do franco-atirador. Rio de Janeiro: Tempo Brasileiro, 1991. Novos pierrôs, velhos saltimbancos: os escritos de Gonzaga Duque e o final do século XIX carioca. $2^{\mathrm{a}}$ ed. Rio de Janeiro: EdUERJ, 2009.

Zola e Gonzaga Duque: o artista e a cidade na virada do século. Crítica Cultural. Santa Catarina, v. 6, n. 1, p. 13-21, jan. 2011. Disponível em:

$<$ http://linguagem.unisul.br/paginas/ensino/pos/linguagem/critica-cultural/0601/060101.pdf $>$. Acesso em 2 de fevereiro de 2014.

QUÍRINO, Tamara. Comentários e críticas de Gonzaga Duque a Pedro Américo. Revista 19\&20, vol. 1, $\mathrm{n}^{\mathrm{o}} 1,2006$. Disponível em <http://www.dezenovevinte.net/criticas/pedro_americo.htm> Acesso em 09 de agosto de 2013.

RANCIÈRE, Jacques. Aisthesis - escenas del régimen del arte. Tradução de Horacio Pons. $1^{\mathrm{a}}$ ed. Buenos Aires: Manantial, 2013.

Políticas da escrita. Tradução de Raquel Ramalhete, Laís Eleonora Vilanova, Lígia Vassalo e Eloísa de Araújo Ribeiro. Rio de Janeiro: Ed. 34, 1995.

O efeito de realidade e a política da ficção. Tradução de Carolina Santos. CEBRAP, $2010 \mathrm{f}$. Disponível em: www.scielo.br/pdf/nec/n86/n86a04.pdf - Acesso em 23 de abril de 2009.

ZOLA, Émile. A batalha do impressionismo. Tradução de Martha Gambini. Rio de Janeiro: Paz e Terra, 1989.

Recebido em 04/02/2016. Aprovado em 04/03/2016.

Title: Mocidade Morta: life in art of XIX Century

Abstract: This essay aims to read the novel Mocidade Morta, by Gonzaga Duque, and do some comparisons between life and art of XIX century. Gonzaga Duque uses some events and characters of his time in his book; this gives the novel a realistic character in art. Throughout the chapters the art will appropriating the "real". If as Rancière (2005) says: the real must be fictionalized to be thought, then the art is a privileged place to think about the life.

Keywords: Mocidade Morta. Life. Art.

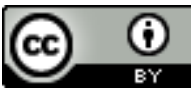

Este texto está licenciado com uma Licença Creative Commons Atribuição 4.0 Internacional. 